\title{
Design of a Multiband Octagonal Patch Antenna
}

\author{
D. Sharmila1*, M. Purnachandra Rao ${ }^{2}$, P. S. V. Subbarao ${ }^{3}$ and S. Nagakishore Bhavanam ${ }^{4}$ \\ 'Department of E and I Technology, Acharya Nagarjuna University, Guntur - 522510, Andhra Pradesh, India; \\ sharmilad@gmail.com \\ 2Department of System design, Andhra University, Visakhapatnam - 530003, Andhra Pradesh, India; \\ raomp17@gmail.com \\ ${ }^{3}$ Departmen of Physics, Andhra University, Visakhapatnam - 530003, Andhra Pradesh, India; \\ raopsvs@rediff.com \\ ${ }^{4}$ Departmen of ECE, Acharya Nagarjuna University, Guntur - 522510, Andhra Pradesh, India; \\ kishore.ece.anu@gmail.com
}

\begin{abstract}
Objectives: Compact and multiband microstrip patch antenna design is essential to meet the huge demand of advanced wireless applications. The objective of the study is to design a serrated structure of patch antenna which is reformed into octagonal shape is proposed to meet the objective. Method: Rogers RT/Duriod $8330\left(\varepsilon_{\mathrm{r}}=2.2\right)$ is used to develop the patch of the proposed antenna. The design is simulated an analyzed by Finite Element Method (FEM) of HFSS software to obtain the output parameters called Returnloss $(<-10 \mathrm{db})$, Voltage Standing Wave Ratio $(1<\mathrm{VSWR}<2)$. Findings: The developed antenna is capable of handling $\mathrm{C}, \mathrm{Ku}, \mathrm{K}, \mathrm{Q}$ and U-band applications in an efficient manner. Applications: This type of antenna will be useful in radar, satellite and mobile applications.
\end{abstract}

Keywords: Octogonal Patch, Returnloss, Serrated Structure, FEM, HFSS, VSWR

\section{Introduction}

The growth in usage of electronic devices in day to day life made changes in wireless communication systems. Increased usage of radars for communication purpose causes demand in small, multi band antennas. Due to this requirement patch antenna technology used widely even though they have narrow band radiation, poor polarization purity, low efficiency, low gain and limited power capacity. Apart from this disadvantages the patch antennas having following advantages. They are low cost, low volume structures, less weight and easy to fabricate. In Some special applications the communication systems such as radars, satellites and GPS (Global Positioning System) are going to be operated in multi frequency applications ${ }^{1}$. At this time the usage of number of different single band antennas can be eliminated by using single micro strip patch antenna.
The design of multiband patch antenna is simple as compared to multi frequency and broad band patch antennas. Due to this a Multiband Octagonal Patch Antenna has been designed for working in six different frequencies presented in multi band $(\mathrm{C}, \mathrm{Ku}, \mathrm{K}, \mathrm{Q}$ and $\mathrm{U}$ bands). Main applications of these bands are used in terrestrial microwave communications such as radar, satellite, aircraft, mobile and space craft communications and for radio astronomy $y^{2,3}$.

\section{Methodology}

In General, micro strip patch antenna consists of three layers: 1. Ground, 2. Substrate and 3. Patch. The ground and patch are metallic plates where the radiation occurs. Serrated structure is a method used to change the shape and size of the patch in terms of length, width and height of the substrate ${ }^{4}$. Serrated structures are useful to make the 
antenna compact and to be operated in multiple bands ${ }^{5,6}$. The dimensions of the proposed serrated structure are calculated by using following mathematical model $^{3}$.

$$
\begin{aligned}
& w=\left(\frac{1}{2 f r \sqrt{\mu o \varepsilon o}}\right) * \sqrt{2 /(\varepsilon r+1)} \\
& L=\left(\frac{1}{2 f r \sqrt{\mu o \varepsilon o \varepsilon e f f}}\right)-2 \Delta L
\end{aligned}
$$

$\Delta L=0.41 h\left((\varepsilon e f f+0.3) /(\varepsilon e f f-0.258) * \frac{\left(\frac{w}{h}+0.264\right)}{\frac{w}{h}+0.8}\right.$

And

$$
\varepsilon e f f=\left(\frac{\varepsilon r+1}{2}\right)+\frac{\varepsilon r-1}{2 \sqrt{1+12(h / w)}}
$$

where, $f \mathrm{r}=$ resonant frequency (in $\mathrm{Hz}$ ), L=length of patch (in $\mathrm{mm}$ ), W=width of patch (in $\mathrm{mm}$ ), h=height of substrate (in $\mathrm{mm}$ ) and $\varepsilon \mathrm{r}=$ relative dielectric constant. Basically $\mathrm{h} / \mathrm{w}<<1$ for better gain and bandwidth ${ }^{7,8}$. With the calculated dimensions, the octagonal shape is proposed as the serrated structure as shown in Figure 1.

\section{Roposed Antenna Design Parameters}

The substrate used in the proposed antenna is Roger RT/ Duriod 8330 with a dielectric constant $\varepsilon r=2.2$ and height (thickness) of substrate, $\mathrm{h}=1 \mathrm{~mm}$. Antenna consists of a single lumped port as input excitation with $50 \Omega$ micro strip line. The measurements of designed antenna are in $\mathrm{mm}$ range. The whole dimension of the designed antenna is 24 $\mathrm{x} 21 \times 1$ (in $\mathrm{mm}$ ). The dimensions are optimized to obtain high gain and performance. The proposed antenna model is designed using HFSS software and shown in Figure 2.

\section{Simulation Results and Discussion}

The Designed Octagonal micro strip patch antenna is simulated and analyzed by FEM method HFSS software.

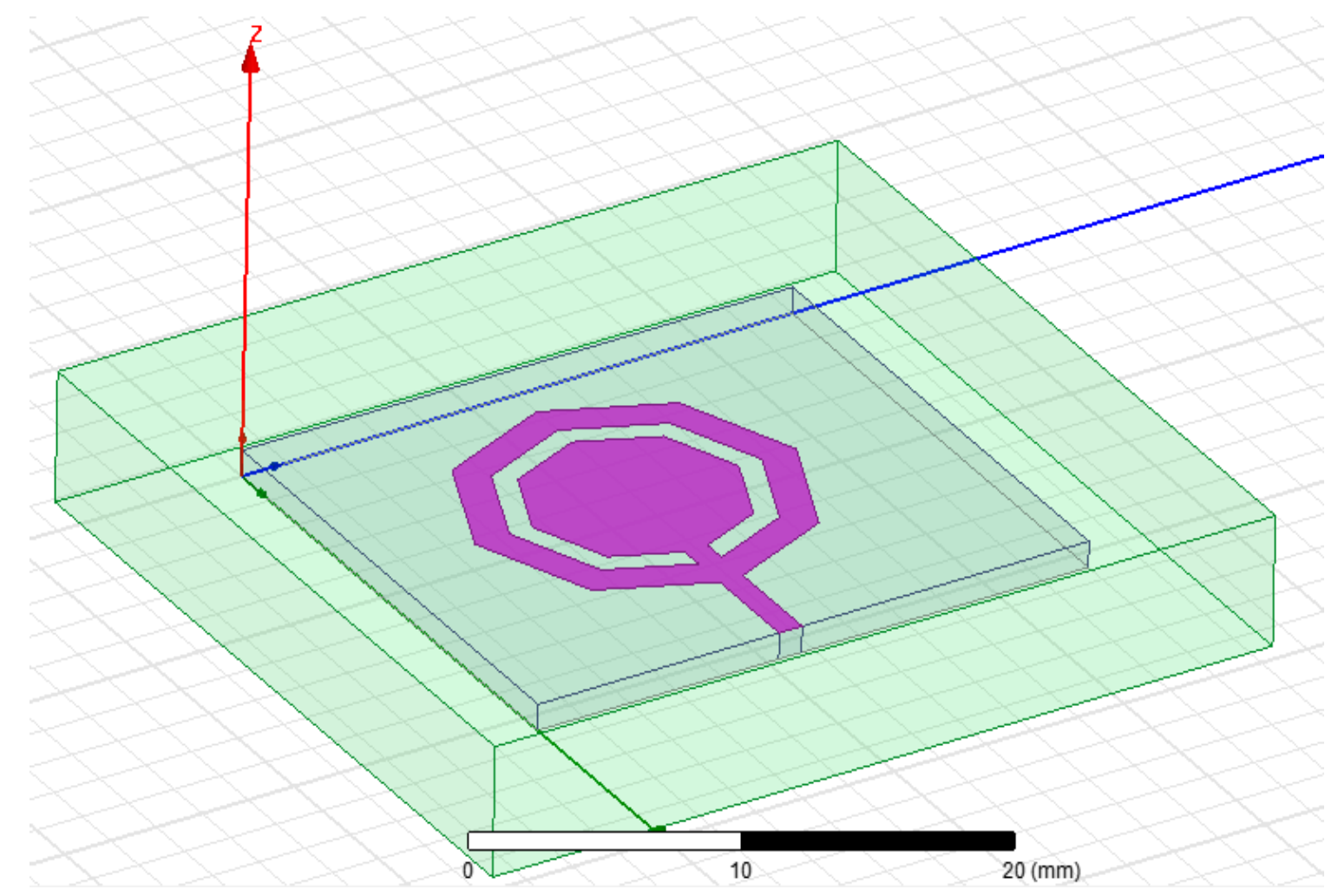

Figure 1. Octagonal patch antenna model. 


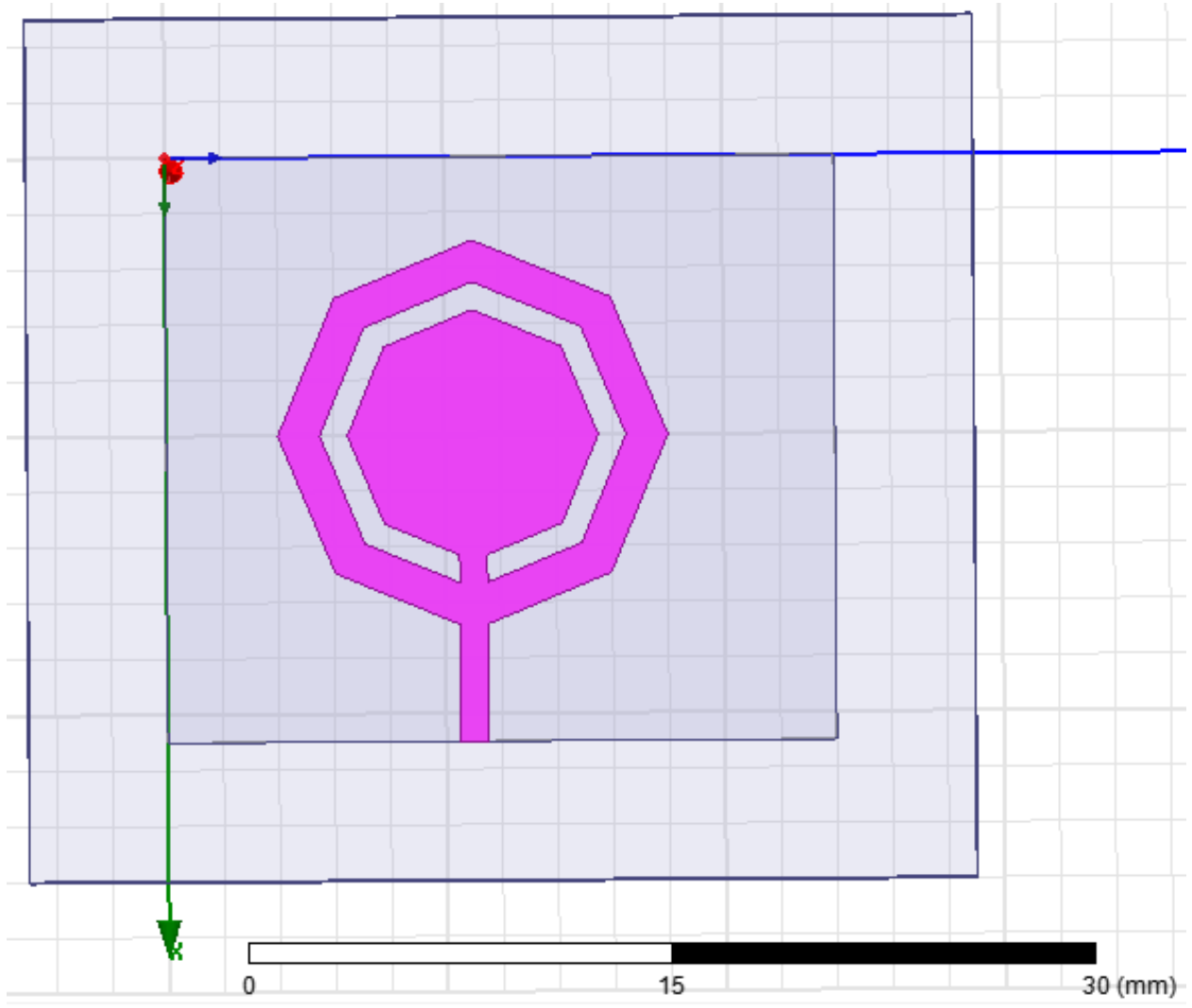

Figure 2. Proposed multi band octagonal patch antenna model top view.

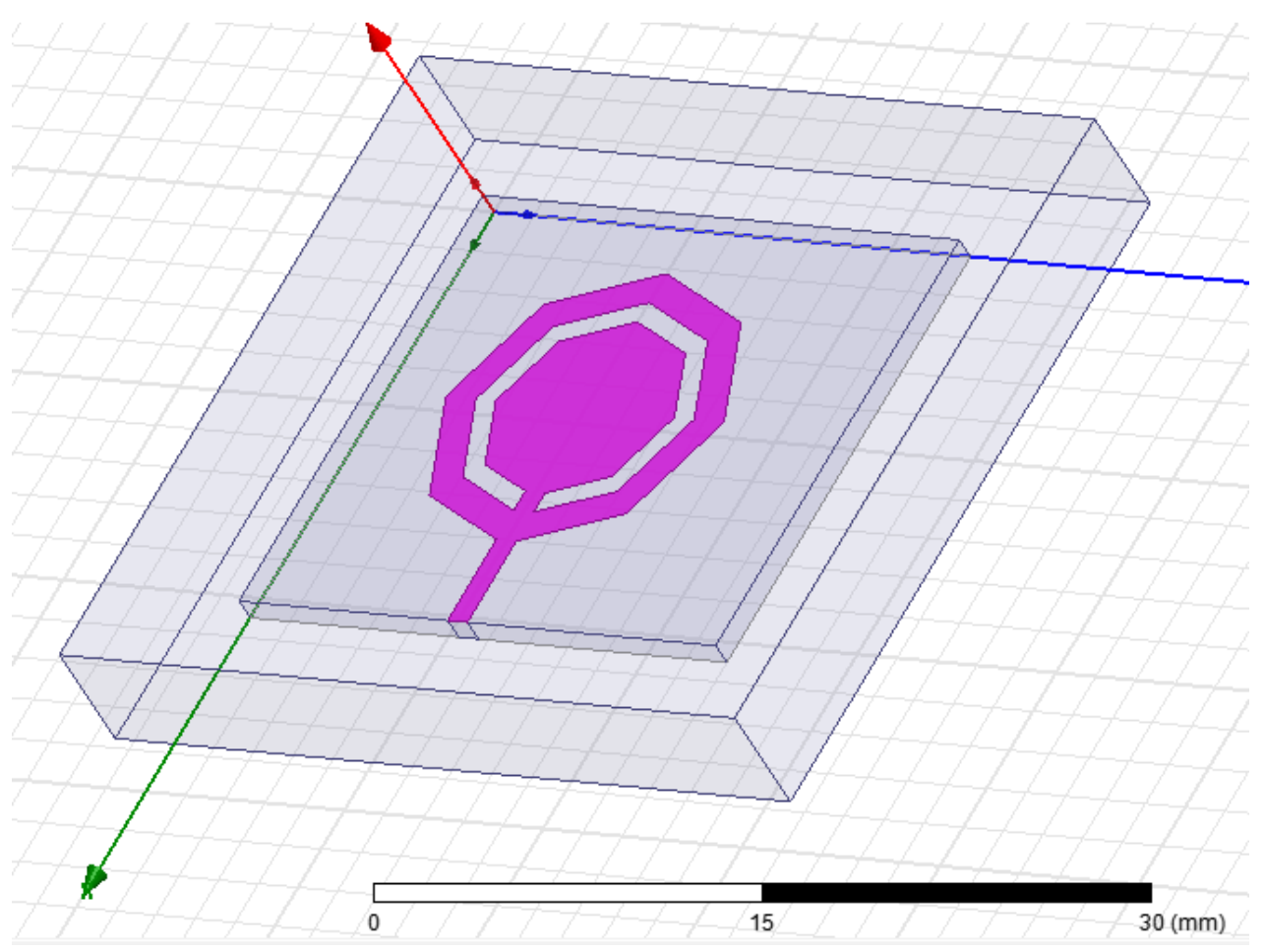

Figure 3. Proposed multi band octagonal patch antenna model side view. 
To achieve better performance, slot should be introduced into patch. The slot is of $0.5 \mathrm{~mm}$ wide which is inserted into the patch as shown in the figure. Single slot was arranged to improve the overall performance in the proposed design as shown in Figure 3.

The overall performance is good at some individual frequencies $7.6 \mathrm{GHz}, 12.0 \mathrm{GHz}, 24.5 \mathrm{GHz}, 37.7 \mathrm{GHz}$, $43.2 \mathrm{GHz}$ and $47.9 \mathrm{GHz}$ with return loss $(<-10 \mathrm{db})$ and $\operatorname{VSWR}(<2)$, Gain $8.6 \mathrm{db}$. The recorded Schematics of return loss, VSWR and overall gain pattern have been recorded. The Designed octagonal patch antenna is applicable to multi band operations without any modification based on the HFSS simulated results.

This antenna is planned and optimized by HFSS. The return loss of the planned antenna is exposed in the Figure 4 and it covers $\mathrm{C}, \mathrm{Ku}, \mathrm{K}, \mathrm{Q}$ and $\mathrm{U}$-bands with frequencies of $7.6 \mathrm{GHz}, 12.0 \mathrm{GHz}, 24.5 \mathrm{GHz}, 37.7 \mathrm{GHz}, 43.2 \mathrm{GHz}$ and $47.9 \mathrm{GHz}$ and a return loss of $-12.2 \mathrm{~dB},-14.0 \mathrm{~dB},-17.4 \mathrm{~dB}$, $-17.8 \mathrm{~dB},-20.5 \mathrm{~dB}$ and $-10.9 \mathrm{~dB}$ respectively.

The VSWR of the antenna at the frequencies $7.6 \mathrm{GHz}$, $12.0 \mathrm{GHz}, 24.5 \mathrm{GHz}, 37.7 \mathrm{GHz}, 43.2 \mathrm{GHz}$ and $47.9 \mathrm{GHz}$ is
$1.6,1.4,1.3,1.2,1.1$ and 1.7 respectively and shown in the Figure 5. The planned antenna haves a stable gain of 8.98dB shown in Figure 6.

\section{Conclusion}

A multi band octagonal patch antenna is presented in this study. This antenna has a close size of $24 \mathrm{x} 21 \mathrm{x}$ 1 (in $\mathrm{mm}$ ), which is informal to be integrated in tiny devices. Results show that the planned antenna covers $\mathrm{C}, \mathrm{Ku}, \mathrm{K}, \mathrm{Q}$ and $\mathrm{U}$-bands transmission at $7.6 \mathrm{GHz}$, 12.0GHz, $24.5 \mathrm{GHz}, 37.7 \mathrm{GHz}, 43.2 \mathrm{GHz}$ and $47.9 \mathrm{GHz}$ respectively and return loss calculated at corresponding frequencies obtained are $-12.2 \mathrm{~dB},-14.0 \mathrm{~dB},-17.4 \mathrm{~dB}$, $-17.8 \mathrm{~dB},-20.5 \mathrm{~dB}$ and $-10.9 \mathrm{~dB}$ and obtained VSWR (Voltage Standing Wave Ratio) values are 1.6, 1.4, 1.3, 1.2, 1.1 and 1.7. The simulated results have a good agreement and the planned antenna can be applicable for wireless communication applications radar, satellite, aircraft, mobile and space craft communications and for radio astronomy.

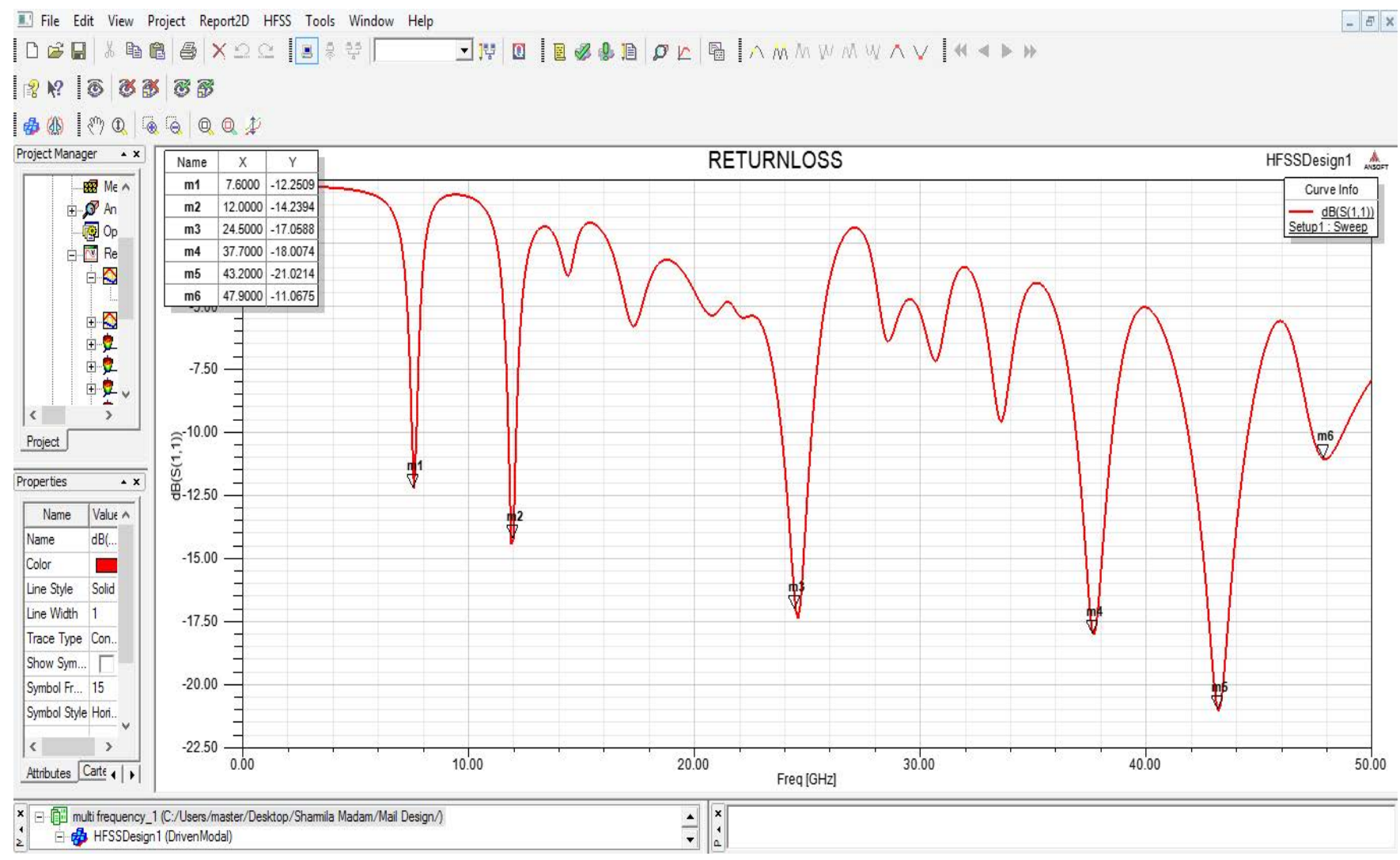

Figure 4. Return loss for proposed multi band octagonal patch antenna model. 


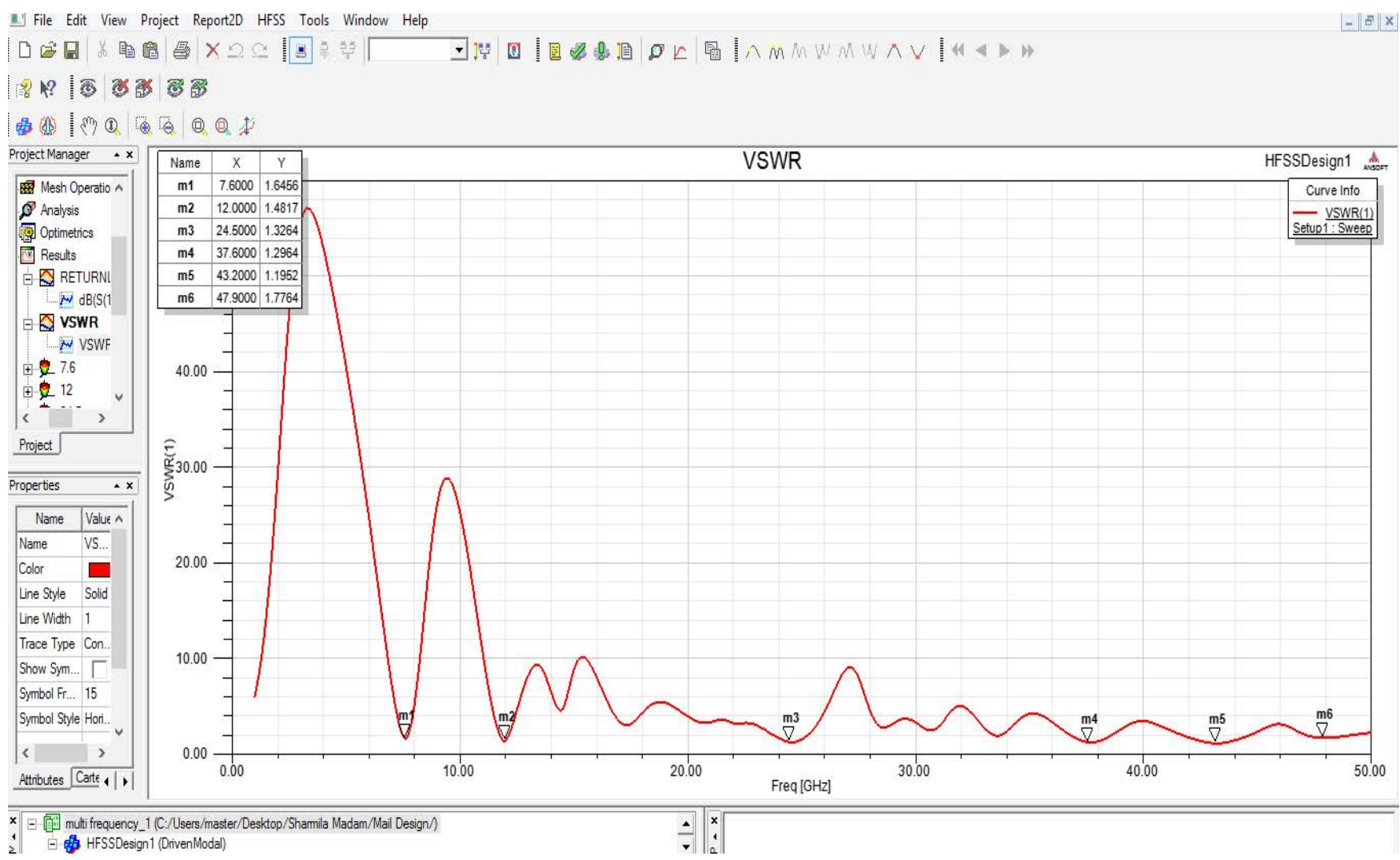

Figure 5. VSWR for proposed multi band octagonal patch antenna model.

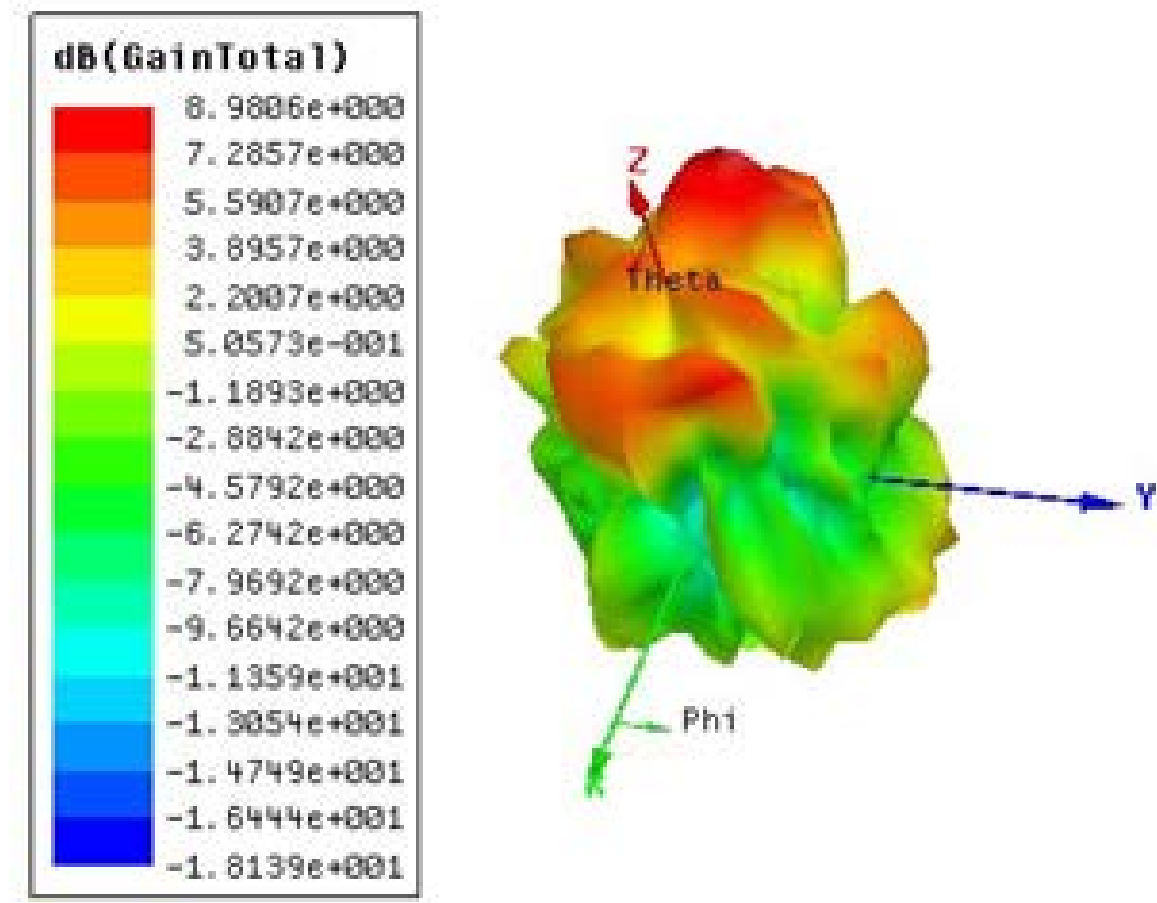

Figure 6. Overall gains for proposed multi band octagonal patch antenna model. 


\section{References}

1. Chakrabarti S, Chakraborty A. Dual-band dual sense microstrip antenna with improved characteristics. In Electronics Letters. 2018; 54(20):1149-50. https://doi. org/10.1049/el.2018.5009

2. Nagakishor BS, Kalyan RS. Design of a novel coaxial-feed triple frequency patch antenna with slots and shorting pin. Procedia Computer Science. 2016; 85:345-51. https://doi. org/10.1016/j.procs.2016.05.242

3. Vasujadevi M, Madhav BTP, Shiva Skandan. Maple leaf shaped array antenna for multiband applications. International Journal of Engineering and Technology (UAE). 2018; 7(1):1-6.

4. Liu X, Wu YZ. A dual-band patchantenna for pattern diversity application. IEEE Access. 2018; 6:51986-93. https://doi. org/10.1109/ACCESS.2018.2870142
5. Vasujadevi M, Naga Kishore BS, Batchu M, Prasanna Kumar A, Maheshbabu. Performance optimization of multiband microstrip patch antenna by incorporating EBG structures. Journal of Advanced Research in Dynamical and Control Systems. 2017.

6. Masood R. Dualmode dual-port pattern diversity antennafor $2.45-\mathrm{GHz}$ WBAN. IEEE Antennas and Wireless Propagation Letters. 2017; 16:1064-7. https://doi. org/10.1109/LAWP.2016.2620724

7. Nagakishore BS. Design and simulation of tripple frequency triangular patch antenna by using HFSS 14.0. International Journal of Applied Engineering Research. $2015 ; 10(20): 18585-8$.

8. Sekhar M, Kishore BSN. Triple frequency circular patch antenna. IEEE International Conference on Computational Intelligence and Computing Research; 2014. p.1231-3. 